\title{
Differences and Similarities of Mental Health Problems Reported by Adolescents: From Greece, Japan, Russia, and Sweden
}

\author{
Saori Nishikawa ${ }^{1,2}{ }^{*}$, Elisabet Sundbom¹, Anna Zashikhina ${ }^{3}$, Spyridoula Lekkou ${ }^{3}$, Bruno Hägglöf ${ }^{3}$ \\ ${ }^{1}$ Department of Clinical Sciences, Division of Psychiatry and Medical Psychology, Umeå University, Umeå, Sweden \\ ${ }^{2}$ Research Center for Child Mental Development, Fukui University, Fukui, Japan \\ ${ }^{3}$ Department of Clinical Sciences, Division of Child and Adolescent Psychiatry, Umeå University, Umeå, Sweden \\ Email: ^saolingon@gmail.com
}

How to cite this paper: Nishikawa, S., Sundbom, E., Zashikhina, A., Lekkou, S., \& Hägglöf, B. (2016). Differences and Similarities of Mental Health Problems Reported by Adolescents: From Greece, Japan, Russia, and Sweden. Psychology, 7, 1658-1670. http://dx.doi.org/10.4236/psych.2016.713157

Received: October 3, 2016

Accepted: November 15, 2016

Published: November 18, 2016

Copyright (๑) 2016 by authors and Scientific Research Publishing Inc. This work is licensed under the Creative Commons Attribution International License (CC BY 4.0).

http://creativecommons.org/licenses/by/4.0/ (c) (i) Open Access

\begin{abstract}
The aims of the present study were to: 1) compare scores and scales of the Youth Self-Report (YSR) reported by healthy adolescents 15 - 17 years of age from Greece, Japan, Russia, and Sweden, 2) analyze gender and age effects of the YSR syndrome scores between and within countries, and 3) compare scores of competence scales and their associations to mental health problems. A comparison of problems ( $\mathrm{n}=$ 812) yields a small effect size of $4.8 \%$ for cross-country in YSR total problems scores. There was a deviation above the overall mean for Greece and Russia, while Sweden and Japan had deviations below the mean. The effect sizes of country for narrowband and broadband scales were small or medium. Analysis within and between countries pointed out some problems that might be more/less common in some countries than others. In their total competence score, Greek adolescents scored higher than Swedish or Japanese. There were some negative associations between syndrome and competence scales across countries. Gender differences were shown across the countries with the exception of Japan. Age differences were less consistent due to the small range of age groups. Even though YSR is used in all four countries, translations and sampling procedure may influence (be one of) the variations.
\end{abstract}

\section{Keywords}

Adolescents, Youth Self-Report, Internalizing and Externalizing Problems, Competence, Cross-National Study

\section{Introduction}

In a rapidly changing and increasingly interconnected world, there have been concerns 
about mental health problems among adolescents in the world. Mental health problems are the significant child health issue no matter the country is wealthy or not (Raffaelli et al., 2013). For the clinical and research purpose, it is important to take account of societal or cultural differences to determine the degree to which differences affect assessment of youthpsychopathology (Achenbach, 2015). Youth Self-Report (YSR; Achenbach, 1991a) is one of the most widely used mental health assessments for children and adolescents, and various studies have shown both similarities and differences across societal/cultural groups. For example, various studies showed that Greeks reported more problems than their Swedish counterparts (Lekkou, Åström, \& Hägglöf, 2006), and adolescents in Cambodia scored higher than Nicaraguan adolescents in the all eight scales expect a withdrawn scale (Medina et al., 2012). Tahmouresi et al. (2014) reported that school children in Iran reported more Internalizing and Externalizing Problems compared to German children. According to the authors, this result could be interpreted from parenting style in Iran, where is less common for Iranian children to express themselves since they are expected to show their respect to maintain harmony in the family. More recently, a study reported that children and adolescents from Thailand and USA reported similar levels of somatic and depressive problems. However, in the clinical samples, Thai children and adolescents reported more somatic problems than their American counterparts (Weiss, Tram, Weisz, Rescorla, \& Achenbach, 2009). Another study showed that Indian adolescents reported more Internalizing and Externalizing Problems compared to Dutch adolescents, while the associations between these scales and the parent-child relationship quality appeared to be similar across the countries (Buist et al., 2016).

A cross-national study of youth from seven countries (Australia, China, Israel, Jamaica, the Netherlands, Turkey, and the United States) indicated that youth from China and Jamaica had the highest mean score of Total Problems and adolescents from Israel and Turkey the lowest (Verhulst, Achenbach, van der Ende, Erol, Lambert, Leung et al., 2003). This study indicated relatively small differences in mean problem scores between countries, and high bicultural correlations between item scores between countries. Rescorla et al. (2007a) showed that self-reported problems across countries were rather similar, with small effect size for differences in 23 societies (e.g., Sweden, USA, and Japan), and that adolescents from Ethiopia, Hong Kong (China), Korea, and Japan scored low in Positive Qualities (i.e., positive worded items which describe desirable characteristics for adolescents). Ivanova et al. (2007) showed an eight-syndrome structure of YSR data, which supports the generalizability of the YSR in different societies, gender, and different age group within societies. It was shown that patterns of cooccurrence of problems reported by YSR items and scales in 23 societies were similar, and Total Problems of 17 countries (e.g., Asia, the Middle East, Europe, and the US) were within one standard deviation of the grand mean.

Age and gender are taken account of differences in multidimensional YSR scales. In general, adolescents in a majority of the countries scored higher scores with the increase of age (Broberg, Ekeroth, Gustafsson, Hansson, Hägglöf, Ivarsson et al., 2001). Gender differences on YSR were similar across the countries, i.e., with girls scoring 
higher than boys on Total Problems and Internalizing Problems and the boys scoring more Externalizing Problems than the girls (Heyerdahl et al., 2004; Lekkou et al., 2006).

A study in Sweden reported that associations between mental health problems and socio-demographic background (e.g., sex, parental education/occupation, family structure, and immigrant status) was rather small, and differed depending on the type of the mental health problems (Stenmark et al., 2015). School experiences in childhood were important determinants of concurrent and later mental health problems (i.e., Internalizing and Externalizing, Attention, and Social Problems) (Waenerlund et al., 2016). For adolescents, studies indicated associations between competence scales and the narrowband syndrome scales from YSR (e.g., Lekkou et al., 2006; Reeslund, 2006). A study showed that Greek adolescents reported higher total competence than their Swedish counterparts (Lekkou et al., 2006). Despite the fact that Total Competence provides important information that is not reflected in the problem scales, little attention has been given to the links between competence scores and syndrome scales. One possibility is that the assessment of competence is highly context dependent, and therefore competence scale may not be appropriate to be used cross-nationally.

According to Achenbach and Rescorla (2007), culture-specific factors (i.e., language, sampling procedure, and characteristics of mental health) may influence the findings from a study of a single country For example, one study showed that Japanese adolescents had a modest response style compared to their Swedish counterparts (Nishikawa, Norlander, Fransson, \& Sundbom, 2007). The numbers of cross-cultural comparisons of mental health problems of youth have been based on other informants, such as parent or teacher reports of the Child Behavior Check List (CBCL; Achenbach, 1991b). Even though cross-cultural consistency of parent-adolescent informant agreement in 25 societies was indicated, adolescents reported significantly more problems than their parents did (Rescorla et al., 2011). Since adolescents have different perspectives on their problems compared to their parents or teachers, parent or teacher reporting cannot fully substitute for adolescents' report of their own problems, especially Internalizing Problems. Another limitation mentioned by Rescorla et al. (2007b) is that low problem scores in some countries might be seen as parents' reluctance to report problems, since self-presentation ("self-serving") is more of a concern in Asian countries, for example, than Euro-American societies (Yabuuchi, 2004).

\section{Objectives}

The aims of the present study were to: 1) compare scores and scales of YSR reported by healthy adolescents 15 - 17 years of age from Greece, Japan, Russia, and Sweden, 2) analyze gender and age effects between and within countries of the YSR syndrome scores, and 3) compare scores of competence scales and their associations to mental health problems.

\section{Methods}

\subsection{Assessment}

Youth Self-Report (YSR, 1991) is a widely used self-report questionnaire designed for 
use with adolescents between the ages of 11 and 18. The first part contains seven competence items, which include the scales Activity, Social Competence, and Total Competence. The second part contains 112 items that measure (a) eight narrowband subscales (Withdrawn, Somatic Complaints, Anxious/Depressed, Social Problem, Thought Problem, Attention Problem, Aggressive Behavior, Delinquent Behavior) and (b) two broadband scales: Internalizing Problems (Withdrawn, Somatic Complaints, and Anxious/Depressed) and Externalizing Problems (Aggressive Behavior, and Delinquent Behavior). Items which are not included in any of the subscales are collected under the heading of Other Problems. The Total Problems scale measures the overall behavioral and emotional functioning of the adolescents. Adolescents are asked to rate each item on a three-point scale from 0 (not true) to 2 (very true or often true). A higher score means more emotional/behavioral problems. The reliability and validity of the YSR are documented by Achenbach (1991a). The YSR has been translated and validated in Greece (Roussos et al., 2001), Japan (Kuramoto, Kanbayashi, Nakata, Fukui, Mukai, \& Negishi, 2002), Russia (Slobodskaya, 1999), and Sweden (Broberg et al., 2001), and each version showed sufficient reliability coefficients and factor structures of the individual scales, which makes possible for cross-national comparisons.

\subsection{Participants}

Greece: The group consists 152 adolescents (61 boys, 91 girls), ages $15-17$ (mean age = 15.99; $\mathrm{SD}=0.94)$. The sampling frame was secondary schools in a city in southern Greece (150,000 inhabitants). Three schools were randomly selected to match the socioeconomic levels (middle) for each population. There was no dropout.

Japan: The group consists 219 adolescents (146 boys, 73 girls), ages $15-17$ (mean age = 16.21; $\mathrm{SD}=0.76)$. The sampling frame was a high school in southern Japan $(240,000$ inhabitants). The study was conducted following the World Medical Association Declaration of Helsinki (World Medical Association, 2008) as the ethical principles for the participants. All participants received informed consent and marked only gender and age. The classes were randomly selected to match the socioeconomic levels (middle) for each population, and adolescents within the age range in the school were invited to participate. There were 6 students $(2.7 \%)$ who did not participate due to absence or dropped out, so the response rate was $97 \%$.

Russia: The group consists 159 adolescents ( 73 boys, 86 girls), aged between 15 and 16 (mean age $=15.40 ; \mathrm{SD}=0.49$ ). The data of the Russian sample was obtained from a group of secondary schools in each of three biggest districts of the city (357,000 inhabitants) in northern Russia. Students were assigned to a school on the basis of their home address within the district. One of three classes in each school was randomly selected to match the socioeconomic levels (middle) for each population. Informed consent was received from the school principal included in the study. There was no dropout.

Sweden: The group consists 282 adolescents (135 boys, 147 girls) aged between 15 and 17 (mean age $=15.80 ; \mathrm{SD}=0.86$ ). The sampling frame was one junior high school and one secondary school in northern Sweden (20,000 inhabitants). These schools were 
the only junior and secondary high schools in the city, so they constitute a total sample. All students between the ninth grade of junior high school and second grade of high school participated. This sample was selected to match the socioeconomic levels (middle). There were two students $(0.7 \%)$ who did not participate due to absence, making the response rate $99 \%$.

\subsection{Data Analysis}

We made within- and between-group analyses. SPSS (2008) (the Statistical Package for Social Sciences) version 16.0 was used for computing descriptive statistics, correlations, and multivariate analysis of variance (MANOVA). ANOVAs for Total Problems, Internalizing and Externalizing Problems, as well as the scores for the eight syndrome scales were performed in a four-(country)-by-three-(ages 15 - 17)-by-two-(gender) factorial design. Effect sizes were expressed as the percentage of explained variance, and were interpreted according to Cohen's criteria (Cohen, 1988) as small (1.0\% to $5.9 \%$ of variance), medium (5.9\% to $13.8 \%)$, and large (13.8\% or more). For each scale that showed significant overall gender or age effects, gender and age differences were tested by separate within-country ANOVAs.

\section{Results}

\subsection{Mean Scores for the Symptom Scales}

Table 1 shows the overall mean score (raw scores) and significant deviations from the overall mean for each country. The mean Total Problems scores for Greece (49.30, SD = 18.32) and Russia $(45.99, \mathrm{SD}=23.79)$ deviated significantly from the overall mean of

Table 1. Significant deviations from overall mean scores in youth self-report scales from four countries.

\begin{tabular}{|c|c|c|c|c|c|c|}
\hline \multirow[b]{2}{*}{ Scale } & \multicolumn{2}{|c|}{ Overall score } & \multicolumn{4}{|c|}{ Significant deviation from overall mean score } \\
\hline & Mean & SD & Greece & Japan & Russia & Sweden \\
\hline Total problems & 42.16 & 20.59 & 7.14 & & 3.83 & -4.49 \\
\hline Internalizing & 13.25 & 8.83 & 3.45 & 1.39 & & -2.8 \\
\hline Withdrawn & 3.55 & 2.50 & .73 & & & -.50 \\
\hline Somatic complaints & 2.97 & 2.68 & & & & -.35 \\
\hline Anxious/depressed & 7.21 & 5.57 & 2.51 & 1.31 & -.92 & -1.75 \\
\hline Externalizing & 13.15 & 7.36 & & -1.67 & 1.79 & \\
\hline Delinquent behavior & 3.68 & 2.92 & & -.97 & .83 & .37 \\
\hline Aggressive behavior & 9.47 & 5.24 & .76 & & .96 & \\
\hline Social problems & 3.08 & 2.43 & -.41 & 1.40 & .55 & -1.05 \\
\hline Thought problems & 2.11 & 2.14 & .69 & -.57 & .43 & -.22 \\
\hline Attention problems & 6.02 & 3.15 & .56 & 1.59 & -.69 & -1.11 \\
\hline
\end{tabular}

Note: $p<.01$. Only significant results are shown. 
42.16. The mean Internalizing Problems scores for Greece $(16.70, \mathrm{SD}=7.93)$ and Japan $(14.64, \mathrm{SD}=9.56)$ deviated significantly from the overall mean of 13.25 , while the mean of Externalizing Problems for Russia $(14.94, \mathrm{SD}=7.99)$ deviated significantly from the overall mean of 13.15. Sweden tended to score less than overall mean scores in most of the scales, with the exception of Delinquent Behavior, while Greece tended to score more than overall mean scores in most of the scales, with the exception of Social Problems.

Results from ANOVAs are displayed in Table 2, which shows F values and effect size for country, gender, age, and their interactions for the YSR Total Problems, narrowband and broadband scales. For Total Problems, country accounted for $4.8 \%$ of the variance, which is a small effect size according to Cohen's criteria (Cohen, 1988). For Internalizing and Externalizing Problems and the eight syndromes scales, ANOVAs revealed significant effects of country on each scale. Country ESs for the subscales ranged from $1.0 \%$ to $13.2 \%$ (see Table 2 ). The ES of country was medium according to Cohen's criteria (Cohen, 1988) for two scales, small for seven scales, and $<1 \%$ for the other scales. The ESs were the strongest in Social Problems (13.2\%) and Attention Problems $(9.4 \%)$.

Gender ESs were significant for Total Problems, Internalizing Problems, subscales of Somatic Complaints, Anxious/Depressed, and Delinquent Behavior. The ESs were small for Somatic Complaints and Anxious/Depressed scales, and $<1 \%$ for the other scales. Overall, girls obtained significantly higher scores than boys on those scales except for the Delinquent Behavior scale, which boys scored higher on than girls.

Table 2. Effects of country, age, and gender in youth self-report scales for adolescents from four countries.

\begin{tabular}{|c|c|c|c|c|c|c|c|c|c|c|c|c|c|c|}
\hline \multirow[b]{2}{*}{ Item } & \multicolumn{2}{|c|}{ Country } & \multicolumn{2}{|c|}{ Gender } & \multicolumn{2}{|c|}{ Age } & \multicolumn{2}{|c|}{$\begin{array}{l}\text { Gender by } \\
\text { country }\end{array}$} & \multicolumn{2}{|c|}{$\begin{array}{l}\text { Age by } \\
\text { country }\end{array}$} & \multicolumn{2}{|c|}{$\begin{array}{l}\text { Age by } \\
\text { gender }\end{array}$} & \multicolumn{2}{|c|}{$\begin{array}{c}\text { Gender by } \\
\text { country by age }\end{array}$} \\
\hline & $\begin{array}{l}\mathrm{F}(\mathrm{df}= \\
3748)\end{array}$ & $\begin{array}{c}\text { ES } \\
(\%) \mathrm{a}\end{array}$ & $\begin{array}{c}\mathrm{F}(\mathrm{df}= \\
1748)\end{array}$ & $\begin{array}{c}\text { ES } \\
(\%) \mathrm{a}\end{array}$ & $\begin{array}{l}\mathrm{F}(\mathrm{df}= \\
2748)\end{array}$ & $\begin{array}{c}\text { ES } \\
(\%) \mathrm{a}\end{array}$ & $\begin{array}{c}\mathrm{F}(\mathrm{df}= \\
3748)\end{array}$ & $\begin{array}{c}\text { ES } \\
(\%) \mathrm{a}\end{array}$ & $\begin{array}{c}\mathrm{F}(\mathrm{df}= \\
5748)\end{array}$ & $\begin{array}{l}\text { ES } \\
(\%) \mathrm{a}\end{array}$ & $\begin{array}{l}\mathrm{F}(\mathrm{df}= \\
2748)\end{array}$ & & $\begin{array}{l}\mathrm{F}(\mathrm{df}= \\
5748)\end{array}$ & $\begin{array}{c}\text { ES } \\
(\%) a\end{array}$ \\
\hline Total problems & $12.56^{* *}$ & 4.8 & $3.88^{*}$ & $.5 \mathrm{~b}$ & 2.59 & - & .44 & - & 2.13 & - & .05 & - & 1.40 & - \\
\hline Somatic complaints & $2.61^{\star}$ & 1.0 & $16.29^{\star *}$ & $2.1 \mathrm{~b}$ & 20.48 & - & .28 & - & 1.00 & - & .77 & - & 1.26 & - \\
\hline Anxious/depressed & $18.69^{* *}$ & 7.0 & $27.05^{\star *}$ & $3.5 \mathrm{~b}$ & 25.05 & - & 2.00 & - & $2.20^{*}$ & 1.9 & .45 & - & 1.05 & - \\
\hline Externalizing & $5.56^{\star}$ & 2.2 & 1.03 & & 1.03 & - & .56 & - & .56 & - & .65 & - & 1.38 & - \\
\hline Delinquent behavior & $11.08^{\star *}$ & 4.3 & $6.62^{*}$ & $.9 \mathrm{c}$ & 6.62 & - & 2.27 & - & .28 & - & .56 & - & .67 & - \\
\hline Thought problems & $9.98^{\star *}$ & 3.8 & 2.66 & & $3.03^{*}$ & $0.8 \mathrm{~d}$ & 1.40 & - & .40 & - & 1.52 & - & 1.73 & - \\
\hline Attention problems & $25.95^{\star *}$ & 9.4 & .01 & & $4.70^{*}$ & $1.2 \mathrm{~d}$ & $4.11^{\star}$ & 1.6 & $2.36^{*}$ & 1.5 & 1.26 & - & $2.87^{\star}$ & 1.9 \\
\hline
\end{tabular}

Note: for Sweden: $\mathrm{n}=282,135$ boys, 147 girls; for Greece: $\mathrm{n}=152,61$ boys, 91 girls; for Japan; $\mathrm{n}=219,146$ boys, 73 girls; for Russia, $\mathrm{n}=160,74$ boys, 86 girls. a: Effect size indicates percentage of explained variance; given only for significant effects. b: Girls scored higher than boys. c: Boys scored higher than girls. d: Older adolescents scored higher than younger adolescents. ${ }^{* *} p<.001 .{ }^{*} p<.05$. 
Significant age effects were found in Withdrawn, Thought Problems, and Attention Problems. An overall tendency was that older adolescents scored higher than younger. However, these ESs accounted for $<2 \%$ of the variance. The within-country analyses revealed significant age differences of the Total, Internalizing Problems, and six syndrome scales (Withdrawn, Anxious/Depressed, Social Problems, Thought Problems, Attention Problems, and Aggressive Behavior) only among Swedish adolescents $(p<.001$ and .05).

There was a significant gender-by-country interaction, which accounted for $<2 \%$ of the variance in Social Problems and Attention Problems. It reflected cultural differences in gender effects. For Social Problems, girls scored higher than boys in all countries but Russia, where boys scored higher than girls. For Attention Problems, girls scored higher than boys in all countries but Greece, where boys scored higher than girls.

A significant age-by-country interaction was shown in Internalizing Problems, Anxious/Depressed, and Attention Problems. For Internalizing Problems and the Anxious/Depressed scale, the interaction reflected an increase by age for Swedish and a small increase for Japanese, and an absence of increase for Greek and Russian. However, these effect sizes were small $(1 \%)$ or very small $(<1 \%)$. For Thought Problems, the interactions reflected differences in the increase in scores with age across countries, with the steepest increases for Sweden and Greece and an absence of increase for Japan and Russia. There was no age-by-gender interaction. There was a three-way interaction between gender-by-culture-by-age on Attention Problems. Figure 1 shows the deviation from the overall mean score for YSR Total Problems for each country by age.

Mean Total Problem Score

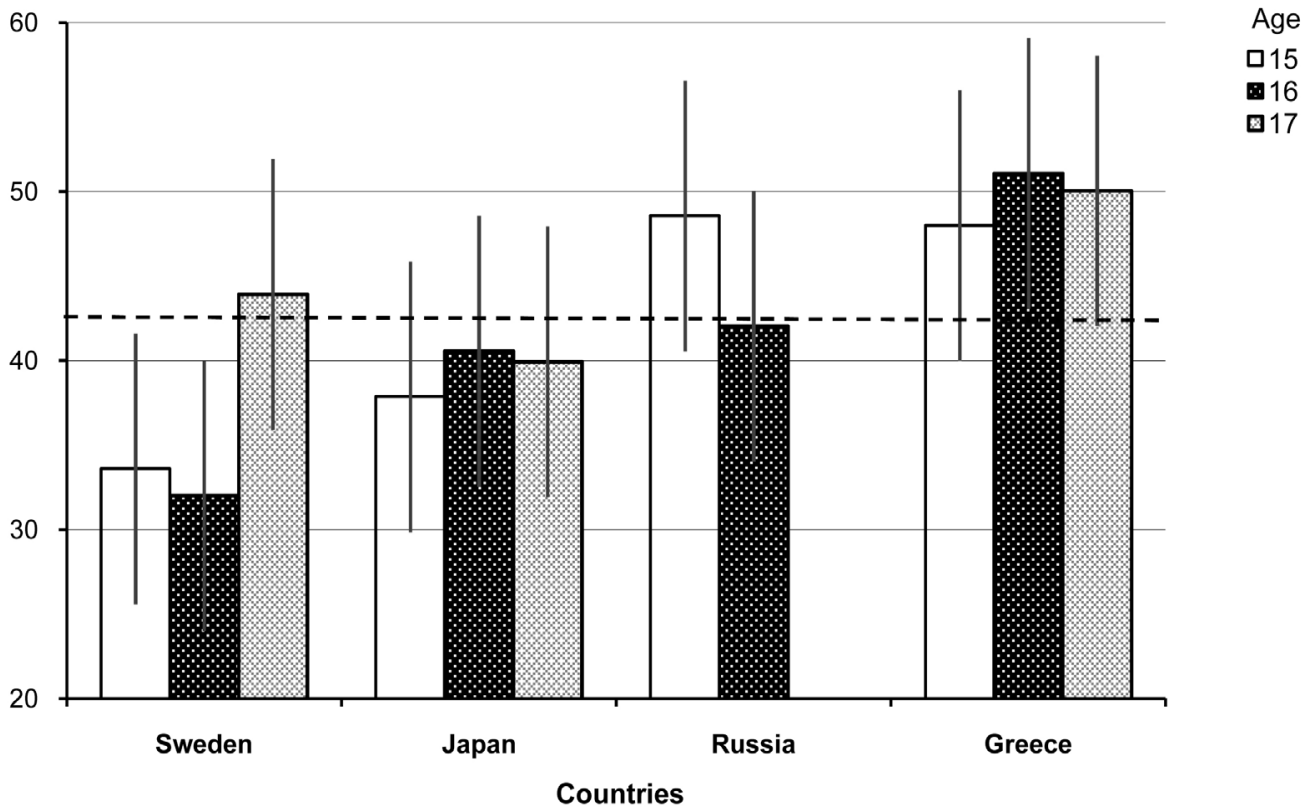

Figure 1. Mean scores for Total Problems in Youth Self-Report of Adolescents from four countries, by age. The line above 40 indicates an overall grand mean. 


\subsubsection{Mean Scores for Competence Scales and Their Associations to Syndrome Scales in YSR}

ANOVAs for scores for the four competence scales were performed in a three-(country)-by-three-(ages 15 - 17)-by-two-(gender) factorial design. ESs were medium (5.9\% to $13.8 \%$ ) or large (13.8\% or more) (Cohen, 1988) and all significant regarding Total Competence (14.6\%), Activity Scale (9.7\%), Social Competence (13.9\%), and Academic Competence $(15.6 \%)$. Japanese youth $(9.28, S D=2.89)$ had significantly lower Total Competence compared to Swedish (11.92, $S D=2.59, p<.001)$ and Greek adolescents (11.84, $S D=2.56, p<.001)$. For Activities and Academic Scales, Greek youth (3.82, $S D=1.36$ for Activities, 2.48, $S D=0.43$ for Academic, all $p<.001$ ) scored significantly higher than Swedish (2.95, $S D=1.35$ for Activities, 2.15, $S D=0.45$ for Academic, all $p<.001)$ and Japanese adolescents $(2.38, S D=1.80$ for Activities, $1.78, S D=0.63$ for Academic, all $p<.001)$. Swedish youth $(6.82, S D=1.82)$ scored significantly higher on Social Competence than Greek (5.57, $S D=1.80, p<.001)$ and Japanese youth (5.11, $S D=1.60, p<.001)$. A significant ES $(1.7 \%, p<.05)$ for gender was received on Social Competence $(p<.001)$, reflecting that boys scored significantly higher than girls, while the girls scored higher than boys on Academic Competence (ES $=0.9 \%, p<.05$ ). There was a country and gender interaction on Social Competence (ES $=2.2 \%, p<.05)$. There were no other two-way or three-way interactions. The post hoc analysis showed a tendency of younger adolescents (15 years old) scoring higher than older adolescents (both 15 and 16 years old) on Total Competence, including Social and Academic Performance $(p<.001$ and .05$)$.

One-way ANOVAs within countries (Greece, Japan, and Sweden) indicated significant gender differences for Greek and Swedish boys, who scored higher on Social Competence and Total Competence (all $p<.001$ and .05), while girls scored higher on Academic Competence (all $p<.05$ ). There was no gender difference among Japanese adolescents.

\subsubsection{Associations between Syndrome and Competence Scales}

To compare the links between syndrome scales and competence scales, Pearson correlations were conducted between the means of the scales or each country. For all countries, Social Competence was negatively associated with Internalizing Problems $(r=$ between -.22 and $-.35, p<.001$, see Table 3). Among Japanese and Swedish adolescents, Academic Competence was negatively associated with Total Problems ( $r=-.16$ and $-.26, p<.05$ and .001 respectively) and Social Competence was negatively associated with Total Problems ( $r=-.18$ for both Japan and Sweden, $p<.05$ and .001 respectively). These results were not found in Greek adolescents.

\section{Discussion}

Comparison of problems reported by adolescents from four countries yield a small effect size for cross-nationally in YSR Total Problems scores. There were deviations above the overall mean for Greece and Russia, while they were below the mean for Sweden and Japan. The effect sizes of country for narrowband and broadband scales were small 
Table 3. Correlations between YSR syndrome scales and competence scales for adolescents from three countries.

\begin{tabular}{ccccc}
\hline & \multicolumn{4}{c}{ YSR competence } \\
\hline YSR syndrome & Total & Activity & Social & Academic \\
\hline Greece & & & & \\
Total problems & -.05 & .13 & -.14 & -.08 \\
Internalizing & $-.18^{*}$ & .06 & $-.30^{* *}$ & -.03 \\
Externalizing & -.03 & .11 & .02 & -.09 \\
Japan & & & & \\
Total problems & -.11 & .04 & $-.18^{*}$ & $-.16^{*}$ \\
Internalizing & -.07 & .11 & $-.22^{* *}$ & -.13 \\
Externalizing & -.03 & .05 & -.06 & -.13 \\
Sweden & & & & \\
Total problems & $-.14^{*}$ & .07 & $-.18^{* *}$ & $-.26^{* *}$ \\
Internalizing & $-.25^{* *}$ & .04 & $-.35^{* *}$ & $-.15^{\star}$ \\
Externalizing & -.02 & .07 & -.18 & $-.20^{* *}$ \\
\hline
\end{tabular}

Note: ${ }^{*} p<.001 .{ }^{*} p<.05$.

or medium. In the Total Competence score, Japanese adolescents scored significantly less than Swedish or Greeks. There were negative associations between syndrome scales and competence scales within countries. The present study showed that effect sizes for differences among countries were in the small to medium range. This result is in agreement with the study by Rescorla et al. (2007a), in which Greece and Russia scored among the highest and Japan and Sweden scored among the middle of the overall mean of the Total Problem score. The effect size of country of the eight syndrome scales yields the largest difference on Social Problems and the smallest for Somatic Complaints. There seem to be specific cultural syndromes e.g., Japanese adolescents reporting low Delinquent and Aggressive Behavior, while Russian youth scored high on Externalizing Problems, including Delinquent and Aggressive Behaviors. The specific syndromes identified in the present study may be explained by the cultural sanction and cultural facilitation model developed by Weisz et al. (2006). Cultural facilitation refers to a particular cluster of behaviors encouraged in one population group more than another and leading to the co-occurrence of these behaviors within the group's behavioral repertoire, while cultural sanction refers to a particular cluster of behavior which is verbally disapproved, negatively sanctioned or punished. Japanese culture emphasizes avoidance of physical aggression and rule-breaking behavior, and there is an obligation on the part of parents and social control regarding delinquency (Tanioka \& Glaser, 1991). In Russian culture, on the other hand, delinquent behavior is valued as promoting status and popularity (Slobodskaya, 1999). Aggressive rule-breaking behaviors are not culturally sanctioned among the Japanese, while socially facilitated among Russians. Youth in Greece in the south of Europe reported themselves the least healthy, while Swedes tended to overrate their health problems (Jürges, 2007). Values in family 
connectedness in e.g., Asian culture was associated with greater tolerance of Internalizing Problems and lower tolerance of Externalizing Problems (Lau et al., 2016). Some countries, like Japan, do not often discuss minds or mental states openly or explain their actions. For example, a study reported that Japanese parents reported more reinforcement to non-anxiety related symptoms than anxiety related symptoms (Essau, Ishikawa, \& Sasagawa, 2011).

Gender differences were similar across the countries, with the exception of Japan. Consistent with various studies (e.g., Broberg et al., 2001; Lekkou et al., 2006; Verhulst et al., 2003), girls scored higher on Internalizing Problems than boys. No gender difference among the Japanese corresponds to the recent result from China (Tepper et al., 2008). An interesting tendency was that in contrast to the traditional psychopathology, the present study showed that among Japanese and Swedish students, girls reported slightly more Externalizing Problems than boys. This result is somewhat surprising given that Sweden is a more gender-equal country than Japan, where there is greater emphasis on traditional gender roles. A possible explanation is that both Japan and Sweden are countries with modern industries and high technology; it may also reflect a changing society in Japan. It was also shown that girls from Sweden, Japan, and Russia reported more Aggressive Behavior than boys, while the boys reported more Delinquent Behavior than girls. Regarding the item of Aggressive Behavior, Japanese girls reported verbal-oriented aggression (e.g., "I talk too much"), while boys reported physical aggression ("I destroy my ownthings"), showing differences within the scale. Age differences were less consistent, with a small range of age group, although there were significant age-by-country effects. Generally, most countries scored higher on most scales with the increase of age.

Associations between competence scales and symptoms support the validity of the scales and correspond well with earlier studies (Broberg et al., 2001). The present results suggested that adolescents who are high in Social Competence were less likely to have problems in Internalizing and Total Problems. Academic Competence was associated with Total Problems among Swedish and Japanese adolescents. One of the explanations for this may be that Swedish (Ollfors \& Andersson, 2007) and Japanese students feel stress or pressure connected to school (Tsuneyoshi, 2013). Greek adolescents reported a higher rate not only of Total Problems but also of Total Competence compared to Swedish and Japanese adolescents. This result could be referred to the result of Lekkou et al. (2006), in which Greek adolescents scored significantly higher than Swedish in Total Problems as well as Self-Esteem. One explanation of no associations between syndromes and competence scales may be that Greek adolescents often receive private lessons for schoolwork and have well-functioning families, which helps them manage their mental health problems (Lekkou et al., 2006). These findings may help to identify areas of impairment associated with mental health problems across countries.

It is important to acknowledge the limitations of this study. First, the sample size was relatively small and cannot be viewed as representative of the entire population. The selection of towns from the various countries was not fully comparable. In the Russian 
sample, there were only 15 - 16-year-old adolescents and lack of the data from competence scales. Second, the small range of the age group limited the age effects. The overall deviations in different adolescent developmental stages across countries are a major question remaining to be further investigation. Third, a lack of other measures might be associated with self-reporting, such as parental or teacher's reports. Fourth, low competence scores among the Japanese may reflect a modest response style (Nishikawa et al., 2007). Furthermore, response bias should be considered in a comparison of the mean values. Translation and sampling discrepancies possibly explain some of the variations. Finally, the present study could not address how social or culture factors within countries might contribute to differences in YSR scores.

\section{Conclusion}

Despite the limitations, the present study provides a coherent picture of adolescent mental health problems in different countries. The results show that there are fundamental measurable differences between countries in terms of mental health problems, although these differences are slight. Analysis within and between countries pointed to particular problems that might be more (or less) common in some countries than others. For example, delinquent behavior appeared as more common among Russian adolescents but less common in Japanese. It is also necessary to consider cultural aspects of parenting i.e., parental use of reinforcement and parent-child communication when dealing with emotional/behavioral problems. These findings could help improve the implications and preventions for adolescents with different cultural backgrounds.

\section{Acknowledgements}

The authors would like to express our appreciation to the students and teachers who made this research possible.

\section{References}

Achenbach, T. M., \& Rescorla, L. A. (2007). Multicultural Understanding of Child and Adolescent Psychopathology: Implications for Mental Health Assessment. New York: Guilford Press.

Achenbach, T. M. (1991a). Manual for the Youth Self-Report and 1991 Profile. Burlington, VT: University of Vermont.

Achenbach, T. M. (1991b). Integrative Guide for the 1991 CBCL/4-18, YSR, and TRF Profiles. Burlington, VT: University of Vermont.

Achenbach, T. M. (2015). Transdiagnostic Heterogeneity, Hierarchical Dimensional Models, and Societal, Cultural, and Individual Differences in the Developmental Understanding of Psychopathology. European Child \& Adolescent Psychiatry, 24, 1419-1422. http://dx.doi.org/10.1007/s00787-015-0795-0

Broberg, A. G., Ekeroth, K., Gustafsson, P. A., Hansson, K., Hägglöf, B., Ivarsson, T. et al. (2001). Self-Reported Competencies and Problems among Swedish Adolescents: A Normative Study of the YSR. European Child and Adolescent Psychiatry, 10, 186-193.

http://dx.doi.org/10.1007/s007870170025

Buist, K. L., Verhoeven, M., Hoksbergen, R., ter Laak, J., Watve, S., \& Paranjpe, A. (2016). Asso- 
ciations of Perceived Sibling and Parent-Child Relationship Quality with Internalizing and Externalizing Problems Comparing Indian and Dutch Early Adolescents. The Journal of Early Adolescence. http://dx.doi.org/10.1177/0272431616653473

Cohen, J. (1988). Statistical Power Analysis for the Behavioral Sciences (2nd ed.). Hillsdale, NJ: Lawrence Earlbaum Associates.

Essau, C. A., Ishikawa, S. I., \& Sasagawa, S. (2011). Early Learning Experience and Adolescent Anxiety: A Cross-Cultural Comparison between Japan and England. Journal of Child and Family Studies, 20, 196-200. http://dx.doi.org/10.1007/s10826-010-9404-5

Heyerdahl, S., Kvernmo, S., \& Wichstrøm, L. (2004). Self-Reported Behavioral/Emotional Problems in Norwegian Adolescents from Multiethnic Areas. European Child \& Adolescent Psychiatry, 13, 64-67. http://dx.doi.org/10.1007/s00787-004-0359-1

Ivanova, M. Y., Achenbach, T. M., Rescorla, L. A., Dumenci, L., Almqvist, F., Bilenberg, N. et al. (2007). The Generalizability of the Youth Self-Report Syndrome Structure in 23 Societies. Journal of Consulting and Clinical Psychology, 75, 729-738.

http://dx.doi.org/10.1037/0022-006X.75.5.729

Jürges, H. (2007). True Health vs Response Styles: Exploring Cross-Country Differences in SelfReported Health. Health Economics, 16, 163-178. http://dx.doi.org/10.1002/hec.1134

Kuramoto, H., Kanbayashi, Y., Nakata, Y., Fukui, T., Mukai, T., \& Negishi, Y. (2002). Standardization of the Japanese Version of the Youth Self-Report (YSR). Japanese Journal of Child and Adolescent Psychiatry, 43, 17-32.

Lau, A. S., Guo, S., Tsai, W., Nguyen, D. J., Nguyen, H. T., Ngo, V., \& Weiss, B. (2016). Adolescents' Stigma Attitudes toward Internalizing and Externalizing Disorders: Cultural Influences and Implications for Distress Manifestations. Clinical Psychological Science, 4, 704-717.

http://dx.doi.org/10.1177/2167702616646314

Lekkou, S., Åström, T., \& Hägglöf, B. (2006). Self-Reported Mental Health and Sense of Coherence among Swedish and Greek Adolescents. Review of Clinical Pharmacology and Pharmacokinetics, 20, i-xiv.

Medina, C. O., Jegannathan, B., Dahlblom, K., \& Kullgren, G. (2012). Suicidal Expressions among Young People in Nicaragua and Cambodia: A Cross-Culturalstudy. BMC Psychiatry, 12, 28. http://dx.doi.org/10.1186/1471-244X-12-28

Nishikawa, S., Norlander, T., Fransson, P., \& Sundbom, E. (2007). A Cross-Cultural Validation of Adolescent Self-Concept in Two Cultures: Japan and Sweden. Social Behavior and Personality: An International Journal, 35, 269-286. http://dx.doi.org/10.2224/sbp.2007.35.2.269

Ollfors, M., \& Andersson, S. I. (2007). Ability of Stress, Sense of Control, and Self-Theories to Predict Swedish High School Students' Final Grades. Educational Research and Evaluation, 13, 143-169. http://dx.doi.org/10.1080/13803610701434241

Raffaelli, M., Lazarevic, V., Koller, S. H., Nsamenang, A. B., \& Sharma, D. (2013). Introduction: Special Issue on Adolescents in the Majority World. Journal of Research on Adolescence, 23, 1-8. http://dx.doi.org/10.1111/jora.12000

Reeslund, K. L. (2006). Parenting Behaviors and Child Social Competence: Risk Factors for Adjustment of Adolescent Offspring of Mothers with and without a History of Depression. Master Thesis, Nashville, TN: Vanderbilt University.

Rescorla, L. A., Achenbach, T. M., Ivanova, M. Y., Harder, V. S., Otten, L., Bilenberg, N. et al. (2011). International Comparisons of Behavioral and Emotional Problems in Preschool Children: Parents' Reports from 24 Societies. Journal of Clinical Child \& Adolescent Psychology, 40, 456-467. http://dx.doi.org/10.1080/15374416.2011.563472

Rescorla, L., Achenbach, T. M., Ivanova, M. Y., Dumenci, L., Almqvist, F., Bilenberg, N. et al 
(2007a). Epidemiological Comparisons of Problems and Positive Qualities Reported by Adolescents in 24 Countries. Journal of Consulting and Clinical Psychology, 75, 351-358. http://dx.doi.org/10.1037/0022-006X.75.2.351

Rescorla, L., Achenbach, T. M., Ivanova, M. Y., Dumenci, L., Almqvist, F., \& Bilenberg, N. (2007b). Behavioral and Emotional Problems Reported by Parents of Children Ages 6 to 16 in 31 Societies. Journal of Emotional and Behavioral Disorders, 15, 130-142. http://dx.doi.org/10.1177/10634266070150030101

Roussos, A., Francis, K., Zoubou, V., Kiprianos, S., Prokopiou, A., \& Richardson, C. (2001). The Standardization of Achenbach's Youth Self-Report in Greece in a National Sample of High School Students. European Child \& Adolescent Psychiatry, 10, 47-53. http://dx.doi.org/10.1007/s007870170046

Slobodskaya, H. R. (1999). Competence, Emotional and Behavioural Problems in Russian Adolescents. European Child \& Adolescent Psychiatry, 8, 173-180. http://dx.doi.org/10.1007/s007870050126

SPSS Inc. (2008). SPSS 16.0 Command Syntax. Chicago, IL: SPSS Inc.

Stenmark, H., Bergström, E., Hägglöf, B., Öhman, A., \& Petersen, S. (2015). Mental Problems and Their Socio-Demographic Determinants in Young Schoolchildren in Sweden, a Country with High Gender and Incomeequality. Scandinavian Journal of Public Health, 44, 18-26.

Tahmouresi, N., Bender, C., Schmitz, J., Baleshzar, A., \& Tuschen-Caffier, B. (2014). Similarities and Differences in Emotion Regulation and Psychopathology in Iranian and German SchoolChildren: A Cross-Cultural Study. International Journal of Preventive Medicine, 5, 52-60.

Tanioka, I., \& Glaser, D. (1991). School Uniforms Routine Activities, and the Social Control of Delinquency in Japan. Youth and Society, 23, 50-57. http://dx.doi.org/10.1177/0044118X91023001003

Tepper, P., Liu, X., Guo, C., Zhai, J., Liu, T., \& Li, C. (2008). Depressive Symptoms in Chinese Children and Adolescents: Parent, Teacher, and Self Reports. Journal of Affective Disorders, 111, 291-298. http://dx.doi.org/10.1016/j.jad.2008.03.013

Tsuneyoshi, R. (2013). Japanese Model of Schooling: Comparisonswith the US. New York: Routledge.

Verhulst, F. C., Achenbach, T. M., van der Ende, J., Erol, N., Lambert, M. C., Leung, P. W. L. et al. (2003). Comparison of Problems Reported by Youths from Seven Countries. American Journal of Psychiatry, 160, 1479-1485. http://dx.doi.org/10.1176/appi.ajp.160.8.1479

Waenerlund, A. K., Stenmark, H., Bergström, E., Hägglöf, B., Öhman, A., \& Petersen, S. (2016). School Experiences May Be Important Determinants of Mental Health Problems in Middle Childhood-A Swedish longitudinal Population-Based Study. Acta Paediatrica, 105, 407-415. http://dx.doi.org/10.1111/apa.13326

Weiss, B., Tram, J. M., Weisz, J. R., Rescorla, L., \& Achenbach, T. M. (2009). Differential Symptom Expression and Somatization in Thai versus US Children. Journal of Consulting and Clinical Psychology, 77, 987-992.

Weisz, J. R., Weiss, B., Suwanlert, S., \& Chaiyasit, W. (2006). Culture and Youth Psychopathology: Testing the Syndromal Sensitivity Model in Thai and American Adolescents. Journal of Consulting and Clinical Psychology, 74, 1098-1107. http://dx.doi.org/10.1037/0022-006X.74.6.1098

World Medical Association (2008). Declaration of Helsinki, Ethical Principles for Medical Research Involving Human Subjects. Seoul: WMA General Assembly.

Yabuuchi, A. (2004). Face in Chinese, Japanese, and US American Cultures. Journal of Asian Pacific Communication, 14, 261-297. http://dx.doi.org/10.1075/japc.14.2.05yab 
Submit or recommend next manuscript to SCIRP and we will provide best service for you:

Accepting pre-submission inquiries through Email, Facebook, LinkedIn, Twitter, etc. A wide selection of journals (inclusive of 9 subjects, more than 200 journals)

Providing 24-hour high-quality service

User-friendly online submission system

Fair and swift peer-review system

Efficient typesetting and proofreading procedure

Display of the result of downloads and visits, as well as the number of cited articles

Maximum dissemination of your research work

Submit your manuscript at: http://papersubmission.scirp.org/

Or contact psych@scirp.org 